Computer Network, Server, Load Balancing

\title{
Analisis Perbandingan Algoritma Static Round-Robin dengan Least-Connection Terhadap Efisiensi Load Balancing pada Load Balancer Haproxy
}

\author{
Hasta Triangga ${ }^{1}$, Ilham Faisal ${ }^{2}$, Imran Lubis ${ }^{3}$ \\ Teknik Informatika, Fakultas Teknik dan Komputer, Universitas Harapan Medan Jl. HM. Joni No.70 C Kota Medan, 20216 Sumatera Utara, Indonesia
}

\section{KEYWORDS}

Load Balancing, HAProxy, Static Round-Robin,

Least connection, Reverse Proxy

\section{CORRESPONDENCE}

Phone: +62 81362139818

E-mail: angga777@gmail.com

\section{A B S T $\mathbf{R}$ A C $\mathbf{T}$}

In IT networking, load balancing used to share the traffic between backend servers. The idea is to make effective and efficient load sharing. Load balancing uses scheduling algorithms in the process includes Static round-robin and Least-connection algorithm. Haproxy is a load balancer that can be used to perform the load balancing technique and run by Linux operating systems. In this research, Haproxy uses 4 Nginx web server as backend servers. Haproxy act as a reverse proxy which accessed by the client while the backend servers handle HTTP requests. The experiment involves 20 Client PCs that are used to perform HTTP requests simultaneously, using the Static round-robin algorithm and Least-connection on the haproxy load balancer alternately. When using Static round-robin algorithm, the results obtained average percentages of CPU usage successively for 1 minute; 5 minutes; and 15 minutes are; $0.1 \% ; 0.25 \%$; and $1.15 \%$ with average throughput produced is $14.74 \mathrm{kbps}$. Average total delay produced 64.3 kbps. The average total delay and jitter is $181.3 \mathrm{~ms}$ and $11.1 \mathrm{~ms}$, respectively. As for the Leastconnection algorithm average percentage obtained successively for 1 minute; 5 minutes; and 15 minutes are $0.1 \% ; 0.3 \%$; and $1.25 \%$ with the average throughput produced is $14.66 \mathrm{kbps}$. The average total delay and jitter is $350.3 \mathrm{~ms}$ and $24.5 \mathrm{~ms}$, respectively. It means Static round-robin algorithm is more efficient than the algorithms Least-connection because it can produce a greater throughput with less CPU load and less total delay.

\section{PENDAHULUAN}

HAProxy merupakan software load balancer yang cukup banyak digunakan karena memiliki lisensi opensource dan berjalan pada sistem operasi linux. HAProxy yang dikonfigurasi sebagai load balancer dengan menggunakan dua atau lebih server backend dapat menambah kemampuan sistem untuk menangani request dari client [1].

Untuk melakukan load balancing, load balancer menggunakan beberapa algoritma penjadwalan antara lain round-robin dan least-connection. Dengan algoritma tersebut laod balancer dapat meneruskan paket permintaan dari pengguna ke server. Misalnya, dengan mengunakan algoritma static Round-robin, load balancer dapat mengirimakan paket koneksi baru yang masuk secara bergantian dan stimultan ke masing-masing server backend. Serta ada juga algoritma least-connection yang dapat mentukan arah lalu-lintas koneksi yang datang ke dalam cluster berdasarkan jumlah koneksi aktif masing-masing server backend [2].
Untuk Mengukur tingkat efisiensi dari load balancing dibutuhkan perhitungan quality of service (QOS) khususnya throughput, delay; Jitter yang dapat memeberikan hasil yang akurat, karena QOS dapat menetukan karakteristik dari koneksi dalam sebuah jaringan [3]. Oleh karena itu penelitian tentang Analisis Perbandingan Algoritma Static Round-robin dengan Leastconnection Terhadap Efisiensi Load Balancing Pada Load Balancer HAProxy menarik untuk dilakukan.

Variabel yang akan dihitung pada penelitian kali ini antara lain: CPU; Throughput; Delay; dan Jitter. Untuk nilai CPU, dan throughput didapat menggunakan server monitoring Zabbix. Sedangkan untuk nilai delay dan jitter didapat menggunakan aplikasi network packet analyzer Wireshark yang selanjutnya dilakukan penghitungan menggunakan rumus delay dan jitter.

Adapun tujuan penelitian ini yaitu menentukan algoritma static round-robin atau least-connection yang akan diaplikasikan pada load balancer HAProxy sehingga diperoleh pembagian beban lingkungan cluster server backend yang lebih efisien. 


\section{HAProxy}

HAProxy merupakan produk software yang dikembangkan untuk melakukan proses load balancing dan failover, dengan kata lain, apabila terjadi kegagalan pada satu node dalam jaringan cluster, Haproxy akan mengalihakan ke node lainnya yang tersedia di cluster tersebut. HAProxy berkerja pada sistem operasi Linux dan memiliki lisensi open source sehingga aplikasi ini dapat dengan bebas dikembangkan oleh para pengembang aplikasi [1].

Untuk melakukan proses load balancing, sebuah load balancer membutuhkan suatu metode dalam proses perhitungannya, disebut scheduling. Ada 8 (delapan) algoritma scheduling HAProxy yang dapat digunakan dalam konfigurasi, yaitu: RoundRobin; Static Round-Robin; Least-Connection; Source; URI (Uniform Resource Identifier); URL_parameter; Header Name; dan RDP Cookie, Namun, fokus dalam penelitian kali ini pada algoritma Static Round-Robin dengan Least-Connection. Dalam melakukan konfigurasi HAProxy, ada bagian-bagian yang perlu diperhatikan, yaitu: Global settings; Default Settings; Fronted Settings; dan Backend Setting. Untuk Algoritma scheduling yang digunakan pada HAProxy terdapat pada konfigurasi Backend setting [4], sedangkan algoritma yang akan digunakan pada penelitian kali ini adalah adalah algoritma static round-robin dan least connection.

\section{Algoritma Static Round-Robin}

Algoritma Static Round-robin atau merupakan algoritma yang bekerja dengan cara mendistribusikan tiap request yang datang ke pool sever-server backend yang sebenarnya, mirip dengan algoritma round-robin DNS. Pada algoritma ini semua node server akan diperlakukan setara sesuai dengan beban yang telah ditetapkan masing-masing server, namun tidak mengizinkan peralihan beban secara dinamis dikarenakan sifat alami beban statis. Tidak ada batasan jumlah server aktif pada backend.

\section{Algoritma Least-Connection}

Algoritma Least-Connection bekerja dengan cara mendistribusikan lebih banyak permintaan (request) ke server asli berdasarkan koneksi aktif yang lebih sedikit, selain itu algoritma ini mengganggap semua server backend memiliki kemampuan komputasi yang sama [2]. Algorima Least Connection cocok untuk digunakan pada cluster dengan lingkungan yang dinamis dengan session yang berubah-ubah [4]. Untuk menggunakan Algorima ini, perintah balance leastconn harus disertakan pada konfigurasi backend settings.

\section{Bandwidth dan Throughput}

Throughput merupakan jumlah bit yang diterima dengan sempurna perdetik pada sebuah perangkat dalam sebuah proses pengiriman data. Sedangkan bandwidth merupakan batasan banyak nya paket data yang bisa dilewati oleh suatu perangkat per satuan detik [5] [6].

\section{Delay dan Jitter}

Delay (latency) merupakan waktu yang dibutuhkan paket data untuk tiba tujuan dalam sebuah proses pengiriman data. Latency dipengaruhi oleh beberapa faktor antara lain: jarak; waktu proses; dan media [3]. Delay dapat dihitung menggunakan persamaan berikut[3][7].

$$
\text { delay }=\frac{\text { PacketLength }}{\text { Linkbanwidth }}
$$

$$
\text { delay }=t_{n}-t_{n-1}
$$

Jitter merupakan variasi delay rata-rata yang diakibatkan banyak kejadian dalam suatu proses pengiriman data seperti panjang antrian dan penghimpunan ulang paket-paket data [3]. Jitter dapat dihitung dengan persamaan berikut.

$$
\text { Jitter }=\frac{\text { TotalVariasiDelay }}{\text { TotalPaketData }-1}
$$

$$
\text { TotalVariasiDelay }=\sum \mid \text { delay }_{n}-\text { delay }_{n-1} \mid
$$

Dengan menghitung Jitter dan delay maka kualitas suatu layanan dalam jaringan dapat diukur [3]. Pembagian kategori Kualitas suatu jaringan dapat dilihat pada tabel berikut.

Tabel 1 Indeks Kualitas Layanan Jitter[3]

\begin{tabular}{|l|l|l|}
\hline Indeks & Nilai Jitter $(\mathrm{ms})$ & Kategori \\
\hline 4 & $0 \mathrm{~ms}$ & Sangat baik \\
\hline 3 & $0 \mathrm{~ms} \mathrm{~s} / \mathrm{d} 75 \mathrm{~ms}$ & Baik \\
\hline 2 & $75 \mathrm{~ms} \mathrm{~s} / \mathrm{d} 125 \mathrm{~ms}$ & Sedang \\
\hline 1 & $125 \mathrm{~ms} \mathrm{~s} / \mathrm{d} 225 \mathrm{~ms}$ & Buruk \\
\hline
\end{tabular}

Tabel 2 Indeks Kualitas Layanan Delay[3]

\begin{tabular}{|l|l|l|}
\hline Indeks & Besar delay $(\mathrm{ms})$ & Kategori \\
\hline 4 & $<150 \mathrm{~ms}$ & Sangat baik \\
\hline 3 & $150 \mathrm{~ms} \mathrm{~s} / \mathrm{d} 300 \mathrm{~ms}$ & Baik \\
\hline 2 & $300 \mathrm{~ms} \mathrm{~s} / \mathrm{d} 450 \mathrm{~ms}$ & Sedang \\
\hline 1 & $>450$ & Buruk \\
\hline
\end{tabular}

\section{METODOLOGI}

Untuk mencapai tujuan penelitian, maka penelitian direncanakan secara sistematis untuk mendapatkan nilai yang seobjektif mungkin, antara lain dengan melakukan perancangan topologi, kemudian masing-masing variabel pada masing-masing algoritma dihitung dan dibandingkan untuk melihat algoritma yang paling efisien antara dua algoritma tersebut. Adapun variabel yang akan diuji adalah: (1) CPU Jumps (2) Throughput (3) delay (4) Jitter. Sedangkan Bandwidth yang digunakan pada masing-masing adalah 1Gbps karena menggunakna koneksi intranet. Adapun langkah-langkah yang akan dilakukan pada penelitian ini adalah sebagai berikut.

\section{Menentukan Topologi}

Penelitian ini melibatkan 20 PC client untuk melakukan request ke server, sedangkan load balancer HAProxy dan server backend berada di area DMZ (demiliterized zone). Rancangan topologi digambarkan dengan tujuan untuk mendapatkan informasi visual tentang tata letak dari perangkat yang digunakan. 


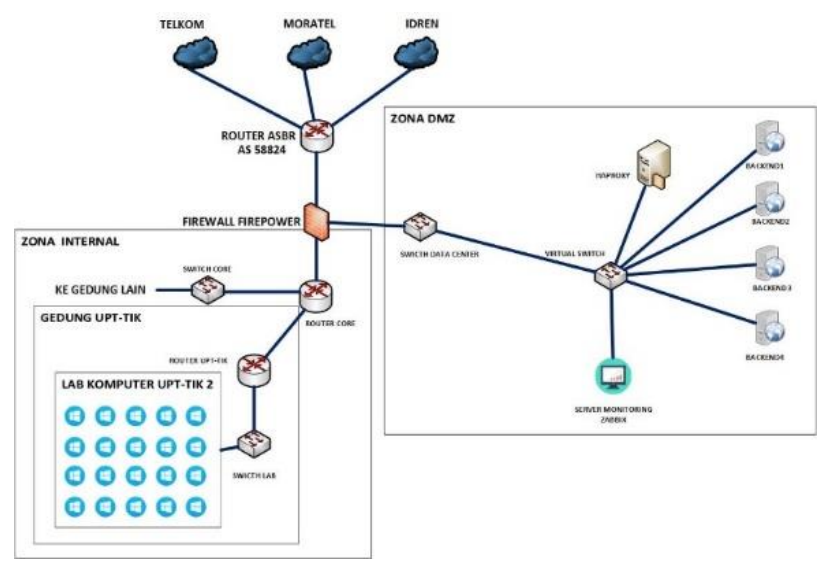

Gambar 1 Topologi Penelitian

Setelah topologi ditentukan, maka selanjutnya adalah memberikan alamat IP pada masing-masing server. Untuk alamat IP komputer client menggunakan DHCP yang sudah ada pada gedung UPT-TIK Universitas Negeri Medan. Berikut adalah datar IP masing-masing perangkat yang digunakan.

Tabel 3 Konfigurasi IP masing-masing server

\begin{tabular}{|l|l|l|l|}
\hline \multicolumn{1}{|c|}{ Mesin } & \multicolumn{1}{|c|}{ IP address } & Subnetmask & \multicolumn{1}{c|}{$\begin{array}{c}\text { Default } \\
\text { Gateway }\end{array}$} \\
\hline client & 15.50 .1 .2 .254 & $\begin{array}{l}255.255 .255 . \\
0\end{array}$ & 15.50 .1 .1 \\
\hline haproxy & 192.168 .250 .2 & $\begin{array}{l}255.255 .255 . \\
0\end{array}$ & $\begin{array}{l}192.168 .250 .2 \\
54\end{array}$ \\
\hline backend & 192.168 .250 .2 & 255.255 .255$. & 192.168 .250 .2 \\
1 & 31 & 0 & 54 \\
\hline backend & 192.168 .250 .2 & 255.255 .255$. & 192.168 .250 .2 \\
2 & 32 & 0 & 54 \\
\hline backend & 192.168 .250 .2 & 255.255 .255$. & 192.168 .250 .2 \\
3 & 33 & 0 & 54 \\
\hline backend & 192.168 .250 .2 & 255.255 .255$. & 192.168 .250 .2 \\
4 & 34 & 0 & 54 \\
\hline Server & 192.168 .250 .1 & 255.255 .255$. & 192.168 .250 .2 \\
monitor & 38 & 0 & 54 \\
\hline
\end{tabular}

\section{Proses Pengujian}

Pengujian kedua algoritma menggunakan 20 PC client dengan cara melakukan request HTTP secara serentak dari 20 PC ke server load balancer Haproxy. data berasal dari server monitoring Zabbix. Data yang diambil nantinya adalah data kejadian terakhir pada grafik CPU dan Network traffic. Sedangkan banyaknya pengujian yang dilakukan adalah sebanyak 5 (lima) kali, hal ini dilakukan agar data yang diperoleh lebih akurat.

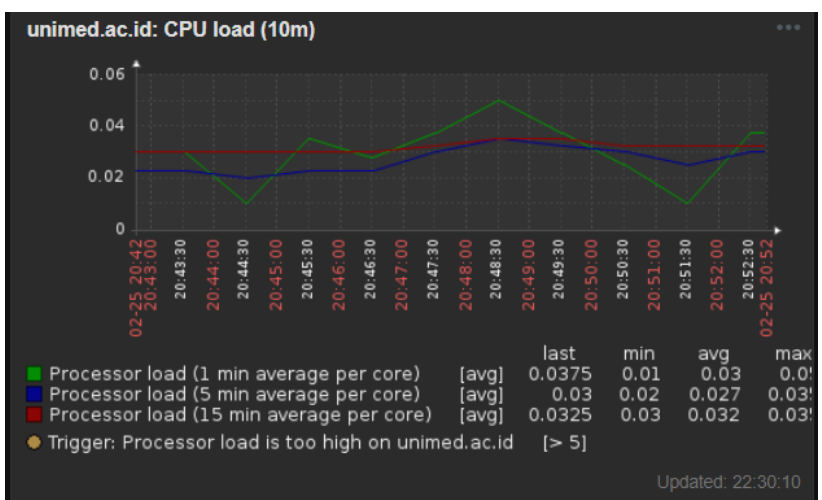

Gambar 2 Grafik CPU Jump Server Haproxy Menggunakan Zabbix

Gambar 2 menunjukkan grafik pengguanaan $C P U$ pada server, beban CPU rata-rata pada 5 menit 10 menit dan 15 menit. Data yang diolah nantinya adalah data last. Data last adalah waktu perkiraan saat server menerima request HTTP dari client. Data yang akan diperoleh dalam bentuk desimal dan akan diubah dalam bentuk persen.

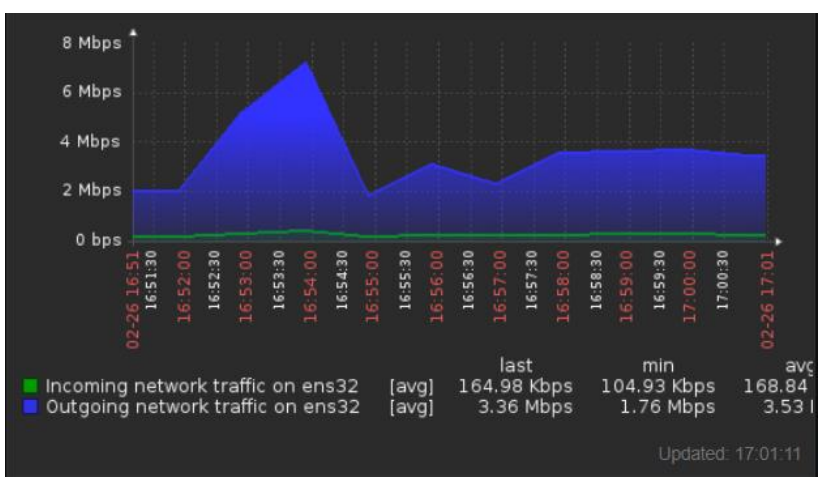

Gambar 3 Grafik throughput interface server

Gambar 3 menunjukkan grafik throughput interface jaringan. Nilai yang akan digunakan nantinya adalah nilai incoming network traffic karena merupakan gafik arus data (throughput) yang diterima server dari user. Sedangkan outgoing network traffic adalah arus data yang berasal dari server ke user.

Variabel selanjutnya yang akan diuji adalah delay dan jitter, untuk mendapatkan nilai variabel tersebut, terlebih dahulu dilakukan monitoring paket data yang menuju haproxy menggunakan wireshark. Untuk mendapatkan paket HTTP ke server haproxy, filter paket dilakukan dengan perintah berikut sehingga diperoleh variabel waktu masing-masing request.

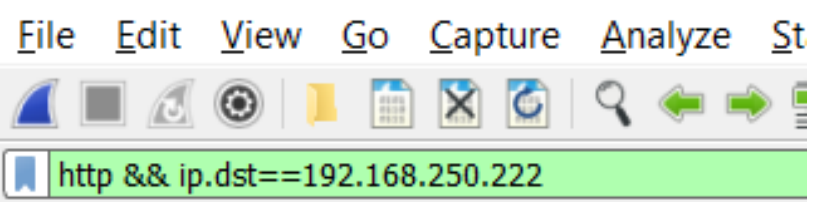

Gambar 4 String Filter Koneksi HTTP Ke Server Haproxy 


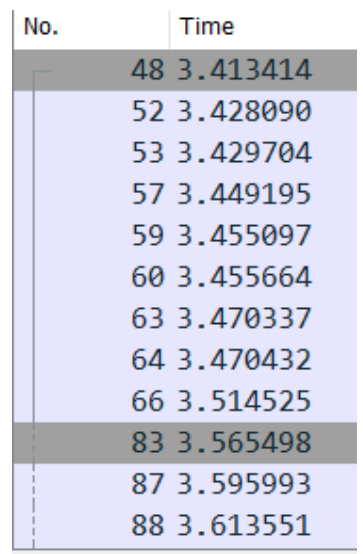

Gambar 5 Variabel Time Dari Pengujian Menggunakan Wireshark

Setelah variabel waktu didapat, maka langkah selanjutnya adalah menghitung delay menggunakan persamaan 2 dan jitter menggunakan persamaan 3 dan 4. Sehingga didapat nilai kualitas layanan (quality of service) pada masing-masing algoritma.

Jika semua variabel didapat, maka hasil pengujian dengan algoritma static round-robin dibandingkan dengan hasil pengujian menggunakan algoritma least-connection. Algoritma yang mendapatkan nilai paling rendah atau kategori QOS yang lebih baik adalah algoritma yang paling efisien untuk digunakan pada load balancer HAProxy.

\section{Hasil dan Pembahasan}

Hasil yang diperoleh dari pengujian $C P U$, Throughput, delay dan Jitter dengan menggunakan algoritma static round-robin dan least-connection adalah sebagai berikut.

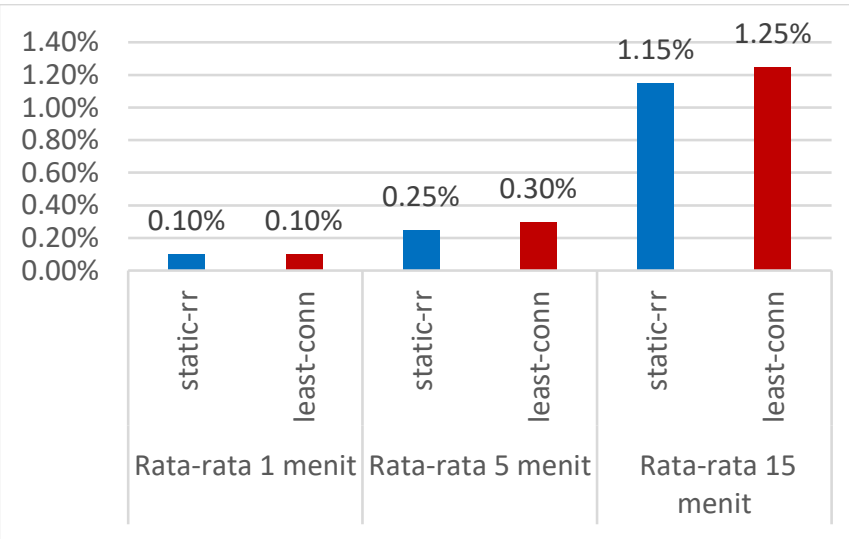

Gambar 6 Grafik Perbandingan CPU Load Antara Algoritma Static-Rr Dengan Algoritma Least-Conn

Dari gambar 6 terlihat bahwa penggunaan beban CPU server haproxy dengan menggunakan algoritma static round-robin dan least-connection sangat minim, baik rata-rata 5 menit, 10 menit, dan 15 menit. Beban CPU bahkan tidak mencapai angka $2 \%$ per core -nya dengan pengujian 20 PC. Namun terdapat sedikit perbedaan pada masing-masing waktu rata-rata beban CPU. Terlihat ketika load balancer menggunakam algoritma static round-robin, penggunaan CPU lebih sedikit $0.05 \%$ dibandingkan dengan ketika server menggunakan algoritma least-connection. Perbedaan lebih terlihat pada waktu rata-rata 15 menit beban
CPU, algoritma static round-robin lebih rendah $0.1 \%$ jika dibandingkan dengan pengunaan algoritma least-connection. Sedang pada throughput didapat hasil sebagai berikut.

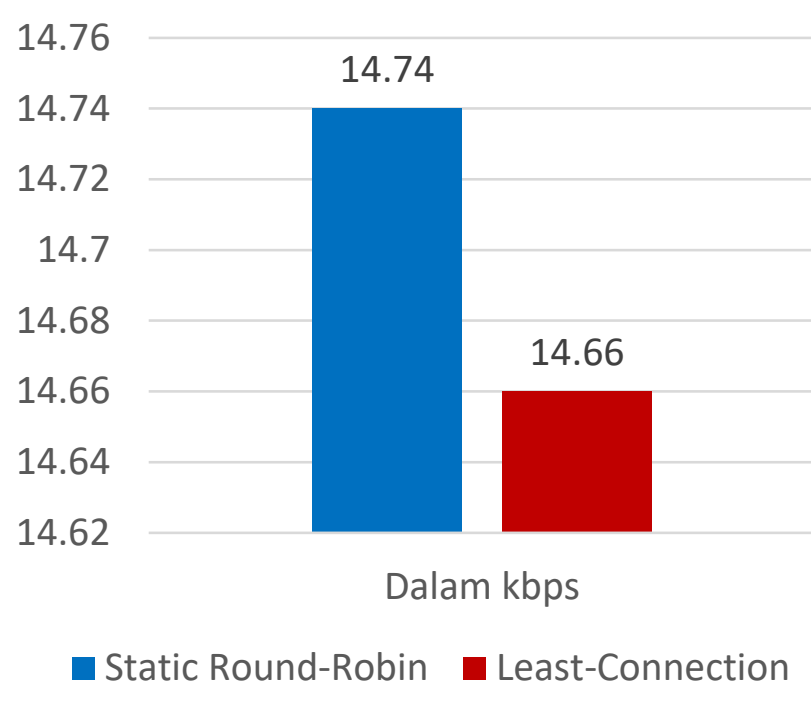

Gambar 7 Grafik Perbandingan Throughput Algoritma Static Round-Robin Dengan Least-Connection

Pada gambar 7 juga terlihat bahwa penggunaan algoritma static$r r$ lebih tinggi throughput-nya 14.74 bernading $14.66 \mathrm{kbps}$ walaupun penggunaan CPU nya lebih kecil.

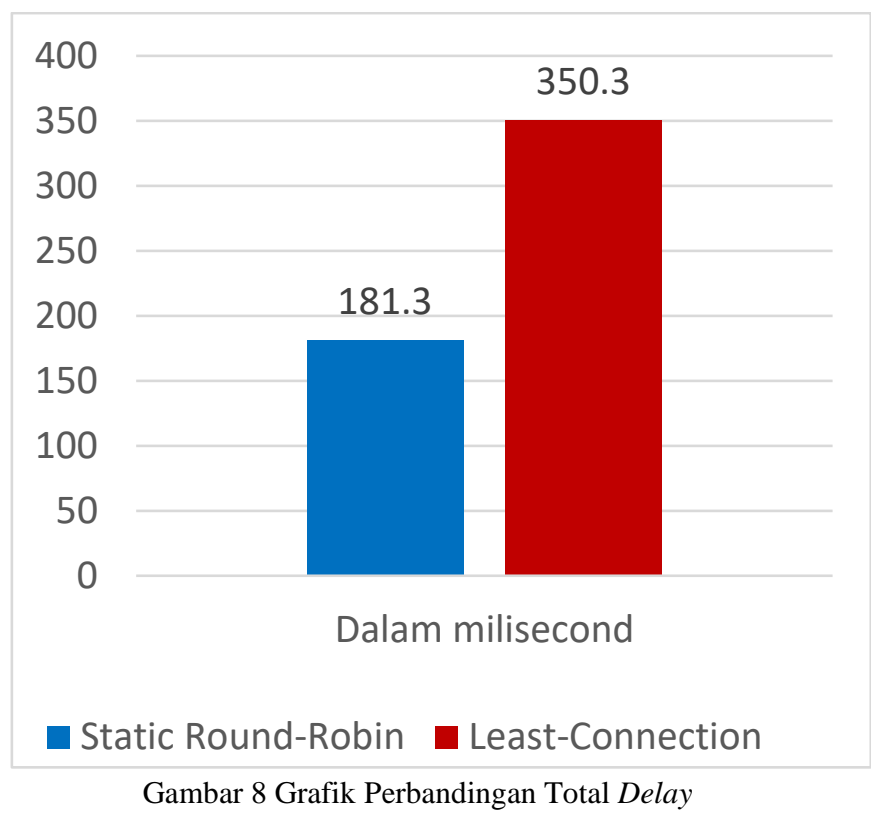

Pada gambar 8 terlihat nilai Total delay pada algoritma Static Round-Robin lebih kecil. Dengan nilai $181.3 \mathrm{~ms}$, pengujian delay pada algoritma static-rr masih dalam kategori baik. Sedangkan untuk Least-connection sudah masuk kategori sedang karena total delay berada pada kisaran 300 - $450 \mathrm{~ms}$. Pada variabel ini penggunaan algoritma Static Round-Robin lebih efisien dibandingkan dengan penggunaan algortima Least-Connection.

Hasil Pengujian berikutnya yang didapat adalah Jitter. Ternyata, Jitter yang diperoleh menggunakan algoritma static round-robin sedikit lebih rendah dibandingkan dengan least-connection. 


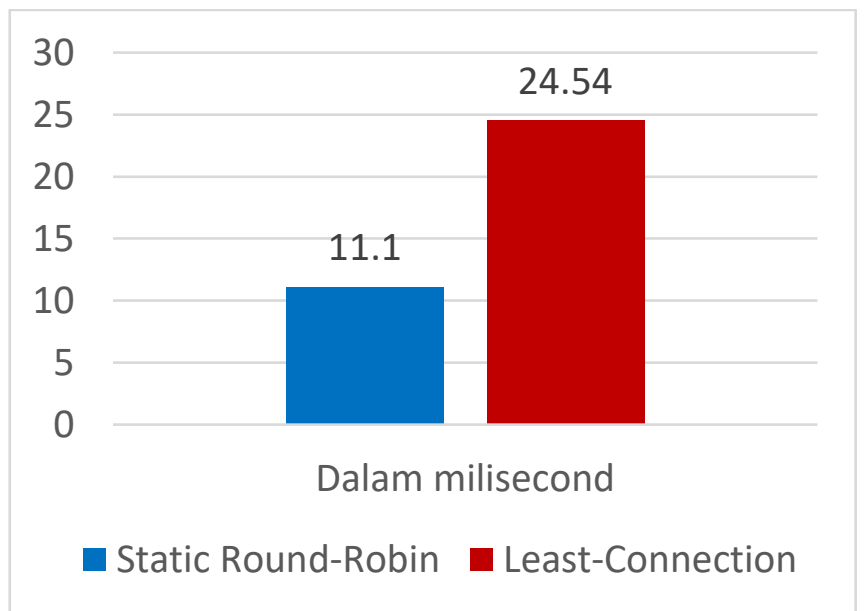

Gambar 9 Grafik Perbandingan Jitter

Pada variabel Jitter, nilai yang diperoleh dari penelitian untuk kedua algoritma masih dikisaran baik karena masih berada dikisaran 0-75 ms. Artinya penggunaan load balancing dengan algoritma Static Round-Robin lebih efisien dibandingkan dengan penggunaan algoritma Least-Connection pada load balancer HAProxy. Jika dibandingkan secara keseluruhan variabel. Maka hasilnya akan terlihat seperti pada tabel berikut.

Tabel 4 Perbandingan Hasil Pengujian

\begin{tabular}{|l|l|l|l|l|}
\hline & $\begin{array}{l}\text { Static- } \\
\text { rr }\end{array}$ & $\begin{array}{l}\text { Kotegori } \\
\text { QoS }\end{array}$ & $\begin{array}{l}\text { Least- } \\
\text { conn }\end{array}$ & $\begin{array}{l}\text { Kategori } \\
\text { Qos }\end{array}$ \\
\hline $\begin{array}{l}\text { CPU Rata-rata } \\
\text { 1 menit }\end{array}$ & $0.10 \%$ & - & $0.10 \%$ & - \\
\hline $\begin{array}{l}\text { CPU Rata-rata } \\
\text { 5 menit }\end{array}$ & $0.25 \%$ & - & $0.30 \%$ & - \\
\hline $\begin{array}{l}\text { CPU Rata-rata } \\
\text { 15 menit }\end{array}$ & $1.15 \%$ & - & $1.25 \%$ & - \\
\hline Throughput & $\begin{array}{l}14.74 \\
\mathrm{~ms}\end{array}$ & - & $\begin{array}{l}14.66 \\
\mathrm{~ms}\end{array}$ & - \\
\hline Total Delay & $\begin{array}{l}181.3 \\
\mathrm{~ms}\end{array}$ & baik & $\begin{array}{l}350.3 \\
\mathrm{~ms}\end{array}$ & sedang \\
\hline Jiter & $\begin{array}{l}11.1 \\
\mathrm{~ms}\end{array}$ & baik & $\begin{array}{l}24.54 \\
\mathrm{~ms}\end{array}$ & baik \\
\hline
\end{tabular}

Pada tabel 4 dapat terlihat persentase CPU yang digunakan sangat kecil, namun sedikit terlihat bahwa penggunaan algoritma leastconnection sedikit lebih tinggi. Sedangkan nilai throughput yang didapat untuk algoritma static round-robin sedikit lebih besar dibandingkan dengan penggunaan least-connection yaitu 14.74 kbps; 14.66 kbps. Namun tidak begitu mencolok karena pengujian yang dilakukan hanya menggunakan 20 (dua puluh) request dari 20 PC client. Untuk variabel delay dan jitter yang diuji, terlihat bahwa total delay dan jitter yang didapat dari penelitian dengan menggunakan algoritma Static Round-Robin lebih kecil yaitu berturut-turut adalah $181.3 \mathrm{~ms}$ berbanding 350 ms, dan 11.1 berbanding 25.54 ms untuk nilai jitter nya.

\section{KESIMPULAN DAN SARAN}

Berdasarkan penelitian yang telah ditentukan dapat disimpulkan bahwa penggunaan algoritma static round-robin lebih efisien. Hal ini ditunjukkan oleh grafik $C P U$ load dimana ketika menggunakan algoritma static round-robin nilai rata-rata yang diperoleh untuk beban CPU sedikit lebih kecil dan throghput lebih besar dibandingkan dengan penggunaan algrotima leastconnection, nilai yang diperoleh untuk beban CPU adalah $0.1 \%$; $0,25 \%$; dan $1.15 \%$; untuk rata-rata 1 menit; 5 menit; dan 15 menit; dan nilai throughput rata-rata adalah $14.74 \mathrm{kbps}$. Nilai total delay dan jitter rata-rata yang diperoleh dari percobaan dengan menggunakan algortima static round-robin juga lebih kecil yaitu masing-masing $181.3 \mathrm{~ms}$ dan $11.1 \mathrm{~ms}$. Nilai hasil Jitter dan Total Delay pada algoritma Static Round-Robin masih masuk dalam kategori baik pada tabel quality of services.

Perbandingan nilai beban CPU dan throughput tidak terlalu terlihat pada hasil penelitian kali ini karena hanya menggunakan 20 PC client untuk melakukan request http. Pada penelitian berikut nya yang berkaitan dengan hal ini, sebaiknya.

a. Pengujian dilakukan dengan cara stress test dengan volume yang lebih besar atau network benchmarking agar perbedaan penggunaan algoritma static round-robin dan leastconnection pada haproxy lebih terlihat.

b. Jika menggunakan load balancer, maka integritas data dari tiap server backend harus tetap terjaga dengan baik sehingga dibutuhkan penelitian lebih lanjut tentang integritas data pada masing-masing server backend.

\section{UCAPAN TERIMA KASIH}

Terima kasih kepada Allah Subhanahu wa ta'ala yang telah meridhai kami untuk menulis penelitian ini, dan juga nabi Muhammad Sallallahu 'Alaihi Wasallam yang telah membawa ajaran agama islam dan menjadi contoh teladan terbaik. Terima kasih juga untuk pada dosen pembimbing jurnal yang telah membimbing saya dalam penulisan karya ilmiah ini. Kepada anak dan istri saya sebagai motivasi tambahan. Dan juga teman-teman di UPT-TIK terutama abangda Mohamad Ihwani dan Oris Krianto Sulaiman yang ikut membantu dalam penelitian ini.

\section{REFERENSI}

[1] A. B. Noviyanto, E. Kumalasari, and A. Hamzah, "Perancangan dan Implementasi Load Balancing Reverse Proxy Menggunakan HAProxy pada Aplikasi Web," J. Jar. Komput., vol. 3, no. 1, pp. 59-68, 2015.

[2] M. E. Mustafa, "Load Balancing Algorithms Round-Robin ( $\mathrm{Rr}$ ), Least- Connection, and Least Loaded Efficiency," vol. 1, no. 1, pp. 25-29, 2017.

[3] R. Wulandari, "Analisis Qos (Quality Of Service) Pada Jaringan Internet (Studi Kasus: Upt Loka Uji Teknik Penambangan Jampang Kulon - LIPI)," J. Tek. Inform. dan Sist. Inf., vol. 2, no. 2, pp. 162-172, 2018.

[4] S. Levine and S. Wadeley, Red Hat Enterprise Linux 7. Red Hat, Inc. and others., 2016.

[5] H. Nasser and T. Witono, "Analisis Algoritma Round Robin, Least Connection, Dan Ratio Pada Load Balancing Menggunakan Opnet Modeler," J. Inform., vol. 12, no. 1, pp. 25-32, 2018. 
[6] G. F. Ardiansa Eko, R. Primananda, and M. H. Hanafi, "Manajemen Bandwidth dan Manajemen Pengguna pada Jaringan Wireless Mesh Network dengan Mikrotik," J. Pengemb. Teknol. Inf. dan Ilmu Komput., vol. 1, no. 11, pp. 1226-1235, 2017.

[7] J. D. Danur, "Analisa Kinerja Jaringan Provider untuk Aplikasi Video Chatting ( Studi Kasus di daerah Marpoyan )," Jom FTEKNIK Jur. Tek. Elektro Univ. Riau, vol. 3, no. 2, pp. 1-8, 2016.

\section{BIOGRAFI PENULIS}

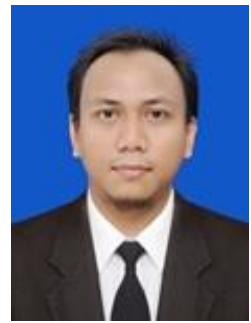

\section{Hasta Triangga}

Lulusan Universitas Harapan Medan pada april 2019. Bekerja di Universitas Negeri Medan sebagai System Administrator sejak 2013 sampai dengan karya ilmiah ini dibuat. 